\title{
TeachActive Feedback Dashboard: Using Automated Classroom Analytics to Visualize Pedagogical Strategies at a Glance
}

\author{
Dana Al Zoubi* \\ Iowa State University \\ dalzoubi@iastate.edu \\ Stephen B. Gilbert \\ Iowa State University \\ gilbert@iastate.edu
}

\author{
Jameel Kelley \\ Iowa State University \\ jkelley@iastate.edu
Aliye Karabulut Ilgu
Iowa State University
aliye@iastate.edu

\author{
Evrim Baran \\ Iowa State University \\ ebaran@iastate.edu \\ Shan Jiang \\ Iowa State University \\ sjiang1@iastate.edu
}

\begin{abstract}
TEACHActive is an automated feedback dashboard that provides instructors with visual classroom analytics about the active learning facilitation strategies they use in their classrooms. We describe TEACHActive system's root requirement of improving pedagogical practices through reflection, the system's process of data flow from an automated observation system, EduSense, to the feedback dashboard, and the technical design of the infrastructure. We designed the TEACHActive dashboard to visualize EduSense's automated observation output and give instructors feedback about their active learning facilitation strategies in their classrooms with the goal of improving their pedagogical practices. We present the TEACHActive prototype development process with three illustrative prototypes.
\end{abstract}

\section{CCS CONCEPTS}

- Applied computing $\rightarrow$ Interactive learning environments; • Human-centered computing $\rightarrow$ Interaction design; Interaction design process and methods; User centered design.

\section{KEYWORDS}

automated systems, classroom analytics, feedback dashboards, pedagogical strategies, human-centered design

\section{ACM Reference Format:}

Dana Al Zoubi, Jameel Kelley, Evrim Baran, Stephen B. Gilbert, Aliye Karabulut Ilgu, and Shan Jiang. 2021. TeachActive Feedback Dashboard: Using Automated Classroom Analytics to Visualize Pedagogical Strategies at a Glance. In CHI Conference on Human Factors in Computing Systems Extended Abstracts (CHI '21 Extended Abstracts), May 08-13, 2021, Yokohama, Japan. ACM, New York, NY, USA, 6 pages. https://doi.org/10.1145/3411763.3451709

\section{INTRODUCTION}

How frequently do instructors receive feedback on their instruction in a regular educational setting? How much of this feedback

\footnotetext{
${ }^{*}$ Corresponding author
}

\section{(c) $($ )}

This work is licensed under a Creative Commons Attribution-NoDerivs International 4.0 License.

CHI '21 Extended Abstracts, May 08-13, 2021, Yokohama, Japan

(c) 2021 Copyright held by the owner/author(s).

ACM ISBN 978-1-4503-8095-9/21/05.

https://doi.org/10.1145/3411763.3451709 captures specific behaviors of instructors and students? Feedback on instruction is one of the most effective mechanisms used to improve instructors' teaching skills [17]. Although expert and peerobservations provide personalized formative feedback to the instructor, these approaches are expensive, unscalable, and not sustainable [1]. Instructors need opportunities for frequent observation, feedback, and reflection on their pedagogical strategies. In a regular classroom, instructors receive no data or information about their own behaviors and they recall very little detail about students' behavior [16]. There is growing evidence supporting that receiving automated and evidence-based feedback about instruction is critical for instructors' professional development [19, 23, 27]. Providing automated observation and feedback about the classroom environment can bridge the gap between what instructors recall about their session and the actual behaviors that took place. One of the main premises of the automated feedback is to empower instructors to make informed decisions about their teaching processes. Learning analytics dashboard applications in education provide benefits for novel feedback opportunities that can enhance learning [6, 33]. Dashboards can be developed to support teachers and/or students by combining design principles and technologies [36]. Automated feedback through dashboards aggregates different indicators about the classroom activities and presents them in multiple visualizations. Feedback dashboards can be used as powerful tools that trigger reflection on instructors' teaching strategies in classrooms.

One particular pedagogy that has strong evidence-based support is active learning $[9,12,26]$. However, teachers typically base their teaching style in part on how they were themselves taught [24] . A systematic method of providing pedagogical feedback is critical for changing this behavior. TEACHActive is an automated feedback system based on classroom analytics that focuses specifically on encouraging active learning strategies. In the current literature on automated instructor feedback, the main emphasis is on the data produced and the instructional outcomes rather than the pedagogy and practices that inform this data [14]. As noted in several reviews on learning analytics dashboards, there is a critical need for research that links pedagogical models with in-class practices to determine ways to improve instructors' implementation and facilitation of teaching practices $[3,5,32]$.

Research suggests that integrating classroom analytics as a feedback mechanism for instructors has a positive impact on instructors' adoption of evidence-based teaching strategies [7]. One of the most critical challenges thus far is the lack of sufficient and data-driven feedback on instructors' pedagogical approaches due to unscalable 
resources [1]. In this research, we address this need by presenting the TEACHActive dashboard that is linked to a pedagogical model to guide instructors with classroom analytics about their active learning facilitation in classrooms. The specific contributions of this paper are based on the iterative design of TEACHActive, a novel feedback dashboard that:

- communicates with an existing multimodal automated classroom observation system, EduSense

- uses pedagogical theory to map automatically collected behavioral classroom indicators to visualized information that is useful to instructors,

- engages instructors for a longer term by including a reflection prompt to set goals and take actions based on their data.

\section{RELATED WORK}

\subsection{Automated Systems in Classrooms}

Ever since Rosalind Picard measured students' confusion and interest levels using a glasses-based sensor on each student [25], there have been multiple attempts to automatically evaluate a classroom situation using sensors. However, a limited number of studies connect with a specific classroom pedagogy [22]. Martinez-Maldonado et al. explore the use of tracking systems to capture classroom data and enable the classification of teachers' pedagogical behaviors [23]. Other studies investigated the use of real-time data to enhance teachers' reflective practice using ambient systems [2] or handheld visualization interface [20].

Researchers at Carnegie Mellon University developed a holistic, classroom sensing system called EduSense that captures audio and video streams using low-cost classroom cameras [1]. EduSense adapts existing computer vision and audio classifiers to detect classroom behaviors. These classifiers include detection of hand raises, body pose, body movement, and speech acts. The EduSense outputs are derived from learning science theories and correlated with effective instruction [1]. However, EduSense does not include a standardized method of presenting its output to instructional stakeholders. We designed the TEACHActive dashboard to fill that gap. Our features of interest include measures based on (a) visual features such as hand raise detection and (b) audio features such as speech detection. These measures are intended to help instructors identify relevant behaviors in classrooms and encourage them to work towards engaging students in active learning strategies.

\subsection{Feedback Dashboards}

Dashboards are increasingly used to support the learning and teaching processes. Few defined dashboards as "a visual display of the most important information needed to achieve one or more objectives; consolidated and arranged on a single screen so the information can be monitored at a glance" (p. 34) [11]. Feedback dashboards are designed to provide information that supports decision making and reflection while increasing awareness about the teaching and learning process [31]. Feedback dashboards hold a promise for improving teaching and learning processes with the evidence-based data they present. In terms of data collection and sources, most studies highlighted university logs as their major data source for the dashboards $[29,30]$. While most of the feedback dashboards are developed to support learning and teaching, few dashboards (if any) addressed the actual impact of these dashboards on instructors' teaching strategies [32].

\section{TEACHACTIVE SYSTEM DESIGN}

In the following sections, we present the development process of TEACHActive dashboard. At a high level, the web-based TEACHActive dashboard consists of the following: a user-facing dashboard (frontend), a server managing requests and running dependencies (backend), information stored in a non-volatile format (database), and auxiliary input systems (cameras with microphones). Each of these components is vital for a proper implementation and evaluation of the system. However, our focus in this paper is the usercentered design process of developing the dashboard user interface. In broad terms, our design of the TEACHActive system is user driven and consists of three phases: (1) gathering user requirements, (2) modeling the process by which the system fulfills these requirements, and (3) the technical design that facilitates the process.

\subsection{User Requirements Pedagogical Improvement through Reflection}

The ultimate goal of users (i.e., instructors in this case) is to improve their pedagogical practices and implement evidence-based active learning practices that are proven to be effective in classrooms. The effectiveness of active learning strategies compared to the traditional lecture approach has been empirically validated and documented in the literature $[9,12,26]$. Reflective practice is a critical catalyst for improving instructional practices as it allows the instructor to identify instructional problems [34]. Self-reflection that occurs through data-informed feedback is of significant importance since it allows making sense of the/ provided evidence $[4,35]$. Using information about learners' actions can help instructors change their pedagogical practices to better engage students [15].

Our preliminary research on instructors' use of active learning strategies in their classrooms revealed a need for addressing their pedagogical change through observation and reflection activities. In the TEACHActive dashboard, we use reflective prompts to promote instructors' reflective practice by (a) gaining a better overview of the in-class activities, (b) setting goals, and (c) addressing pedagogical changes in their sessions. The reflective prompts also allow instructors to track their progress and behavioral changes from one session to another.

\subsection{System Process: Data Flow from EduSense to Dashboard}

The system process is designed to fulfill the user requirements by capturing behavioral indicators of active learning strategies via the automated system, EduSense, and presenting the classroom data analytics on the feedback dashboard TEACHActive. As such, the raw output data from EduSense is presented as meaningful visual classroom analytics on the dashboard. EduSense captures data from classroom behaviors through audio and visual modules. We chose the following classroom behavior features from EduSense to output as classroom analytics: sit vs stand, hand raises, movement 
Table 1: Data Captured, description, classroom analytics and examples of behavioral indicators in classrooms

\begin{tabular}{|c|c|c|c|}
\hline Data Provided by EduSense & Description & $\begin{array}{l}\text { Classroom } \\
\text { Analytics }\end{array}$ & $\begin{array}{l}\text { Behavioral Indicators of Active } \\
\text { Learning in Classrooms }\end{array}$ \\
\hline Sit vs. Stand & $\begin{array}{l}\text { This feature provides information } \\
\text { about changes in classroom activity }\end{array}$ & $\begin{array}{l}\text { Changes in } \\
\text { classroom activity } \\
\text { (Behavioral } \\
\text { Engagement) }\end{array}$ & $\begin{array}{l}\text {-Instructors are more likely to stand in } \\
\text { front of desks and/or walk among } \\
\text { students. } \\
\text {-Students are more likely to be working } \\
\text { in groups } \\
\text {-Various changes in class activity [13] }\end{array}$ \\
\hline Hand Raises & $\begin{array}{l}\text { This feature provides information } \\
\text { about the frequency of hand raises } \\
\text { which is an indicator of student } \\
\text { participation }\end{array}$ & $\begin{array}{l}\text { Student } \\
\text { participation } \\
\text { (Behavioral } \\
\text { Engagement) }\end{array}$ & $\begin{array}{l}\text { High frequency of hand raises } \\
\text { associated with high levels of student } \\
\text { participation [28] }\end{array}$ \\
\hline Body position & $\begin{array}{l}\text { This feature provides information } \\
\text { about instructor and student location } \\
\text { through spatial data. This spatial data } \\
\text { can detect actions that are occurring } \\
\text { more frequently in one area of the } \\
\text { classroom. }\end{array}$ & Spatial Data & $\begin{array}{l}\text { Instructors move between the right and } \\
\text { left sides of the class [18] }\end{array}$ \\
\hline Accelerometer & $\begin{array}{l}\text { This feature provides information } \\
\text { about movement. }\end{array}$ & $\begin{array}{l}\text { Kinesthetic } \\
\text { patterns }\end{array}$ & $\begin{array}{l}\text { Instructors have increased body } \\
\text { movements [25] }\end{array}$ \\
\hline Student vs Instructor & $\begin{array}{l}\text { This feature provides information } \\
\text { about the patterns and ratio of } \\
\text { student vs instructor speech }\end{array}$ & $\begin{array}{l}\text { Behavioral } \\
\text { engagement } \\
\text { (student } \\
\text { participation) }\end{array}$ & $\begin{array}{l}\text {-low frequency of instructor talk } \\
\text {-high frequency of student talk } \\
\text {-Ratio of student vs instructor talk is } \\
\text { high [8]. }\end{array}$ \\
\hline Speech Act Delimiting & $\begin{array}{l}\text { This feature provides information } \\
\text { about the frequency and duration of } \\
\text { speech }\end{array}$ & $\begin{array}{l}\text { Behavioral } \\
\text { Engagement } \\
\text { (student } \\
\text { participation) }\end{array}$ & $\begin{array}{l}\text {-Effective intervals of silence during } \\
\text { instruction } \\
\text {-High frequency of student talk } \\
\text {-Short intervals of instructor talk [10] }\end{array}$ \\
\hline
\end{tabular}

patterns, student vs instructor speech, and speech act delimiting. The TEACHActive dashboard links the active learning pedagogical model to the classroom analytics data captured from the behavioral indicators of instructors and students. These analytics help instructors identify their actual behaviors in classrooms and encourage them to work towards engaging students in more active learning strategies. Instructors' facilitation behavior is an outcome measure of their kinesthetic patterns, changes in class activity such as sitting vs standing, and spatial data from body positions. Students' behavioral engagement is measured from the number of hand raises, student vs instructor speech, frequency and duration of speech. Table 1 shows classroom analytics with examples of behavioral indicators in active classroom.

\subsection{Technical Design Infrastructure}

The TEACHActive system was created utilizing discrete systems working in union. The modalities of data conveyed from our data source, EduSense, to our visual dashboard includes both visual and audio data. The project has these data flowing unidirectionally from the input systems to the EduSense system for analysis and storage, to our system for data aggregation, transformation, and further analysis, and finally to the dashboard for display. The dashboard component utilizes the JavaScript framework, React, for its declarative and component-based architecture that enables modularization and reusability when developing prototypes and revisions. The frontend communicates with the backend through REST and GraphQL requests to internally exposed ports on the server hosting the EduSense system. These requests are secured over the HTTPS protocol using certificates from inside the university network. The backend and EduSense system are running on a Dell PowerEdge R740 with two Intel Xeon Gold 5218 processors and uses NVIDIA GForce RTX 3090 graphics card. The EduSense system is running in parallel on the server performing analysis on the incoming camera streams and storing the data it gathers in a Mongo database to be queried by the frontend. The cameras are networked and streaming video over HTTPS and encoded in High Efficiency Video Coding (HEVC). To address privacy and security measures for our system implementation, we ensured secure access to the cameras by keeping them within the university network as well as sending video streams over HTTPS rather than RTSP; thus encrypting those streams. Access to the server is restricted by use of SSH keys on the university network. In this production, the system will not archive classroom audio and video data long term; instead it will delete those files after processing. We secured 
access to the featured data by associating it with Web API- HTTPS with user authentication and access control. We ensured that only authenticated instructors can access their class data by requiring an authenticated login through Okta.

\section{TEACHACTIVE PROTOTYPE DEVELOPMENT PROCESS}

We used a human-centered design (HCD) process that aims to make interactive systems more usable by focusing on the use and usability through direct input from the users [21]. This participatory process optimizes the design of interactive systems to the needs of users through iterative cycles. In our context, the TEACHActive users are university engineering instructors. We carried out this process in three main stages: (1) Understanding the context of use, (2) building design consensus, and (3) illustrating interactive prototypes. In Stage 1, in order to understand the context and needs of engineering instructors, we first conducted a needs analysis $(n=53)$ and a followup interview $(n=4)$ that aimed at understanding instructors' use of active learning strategies and implementation in their classrooms. In Stage 2, we validated the context of active learning in engineering classrooms with the literature findings. We conducted periodic meetings and created design priority specifications that combined our findings with the possible data that can be captured by the system. In Stage 3, we illustrated the different versions of prototypes based on our findings from the surveys, literature and user walkthroughs. In the following section we present the Stage 3 process, the interactive prototypes, and the changes made based on the user-walkthrough feedback.

\subsection{First Prototype}

Based on the needs analysis, survey findings with validation from the literature about behavioral indicators for active learning strategies in classrooms, and their alignment with the data that can be provided from EduSense, we developed the first dashboard prototype (Figure 1). The instructor completes their 51-minute teaching session and receives this feedback classroom analytics. The instructor completes their 51-minute teaching session and receives this feedback classroom analytics. They see two screens: Session (at left) and Progress (at right). The visuals on the Session screen identify the following numeric metrics: a total of eleven hand raises (which was more than the last session they taught - the upward arrow), the total number of minutes they spoke in class were 20 minutes (less than last session), the total time of student speech (31 minutes, increased from last session) and student performance (average grade increased by 6 points). There is a pie chart that indicates the level of engagement that illustrates the four phases based on the four components of the ICAP framework: interactive, constructive, active, passive [8]. The active learning facilitation behavior is represented by scatter plot. In the Progress screen, there were two cumulative visuals about their four sessions. Based on the feedback from the user walk-throughs, instructors could not really make sense of the pie chart that was aligning the ICAP framework from the literature. It was not clear how to identify the extracted data under the categories of active, passive, constructive or interactive. The facilitation behavior scatter plot was also not indicative of any meaningful behavior; rather it was perceived as a broad term. Also, the six point increase in the student performance was not that meaningful or something that instructors perceived as helpful to act upon for the next session. The progress report was also perceived less comparative than the expected comparative between sessions. Accordingly, we iterated the first prototype to make the dashboard more meaningful and more specific based on the feedback we received.

\subsection{Second Prototype}

The second prototype (Figure 2) was developed according to the feedback received from the first prototype user walk-through. An instructor receiving the second prototype would be able to navigate between the Session and the Progress screen through the left menu bar similar to the first prototype. The four metrics displayed on the top of the window metric shows the unit correlates to the session selected. In this case, there were 11 hand raises, 39 mins of instructor speech, 11 minutes of student speech, and a class performance score of $85 \%$. Changes made included adding the total length of the session, shown as the denominator of a fraction in both instructor and student speech metric components (50 min). Also, next to each metric there was an upward or downward arrow with a number that allows users to track their progress from one session to another. This was based on the users' feedback to allow a more meaningful track of change between sessions.

For example, the number of hand raises in this session was increased by two from their last session as shown to the right of the total number of hand raises in the session. Due to the feedback about the confusion that the pie chart corresponds to the ICAP framework in Prototype 1, we replaced the student engagement (Figure 1) with in class activity patterns (Figure 2). The in-class activity patterns include a dropdown where the instructor can select between sit vs stand and kinesthetic patterns (movement patterns). For example, selecting the sit vs stand in Figure 2, instructors can realize that they were standing more at the middle and end of class than at the beginning. If they use the dropdown to select "Kinesthetic/Movement Patterns" they can also see a bubble chart that indicates where they spent the most time in the classroom. This figure indicates that the instructor favored standing on the left side of the classroom (the largest bubble). We also replaced the facilitation behavior that was perceived as a vague indicator with behavioral engagement. Depending on the selected metrics (hand raises, instructor speech, and student speech), instructor can view the engagement of the class over time. Additionally, we created the activity times (gray columns) that identify when an in-class activity occurred, which was perceived as an indicator of a meaningful change in the data. Changes in the progress screen included adding bar graphs that compare the behavioral engagement of students between different sessions. Bar graphs were used since they were perceived as more meaningful to illustrate the comparison between sessions.

\subsection{Third Prototype}

In Prototype 3 (Figure 3), changes included adding a notification, as a reflection prompt, that allowed instructors to set goals that may encourage changes in their pedagogical practices. As an example, the instructor receives this after teaching their session and sees that 


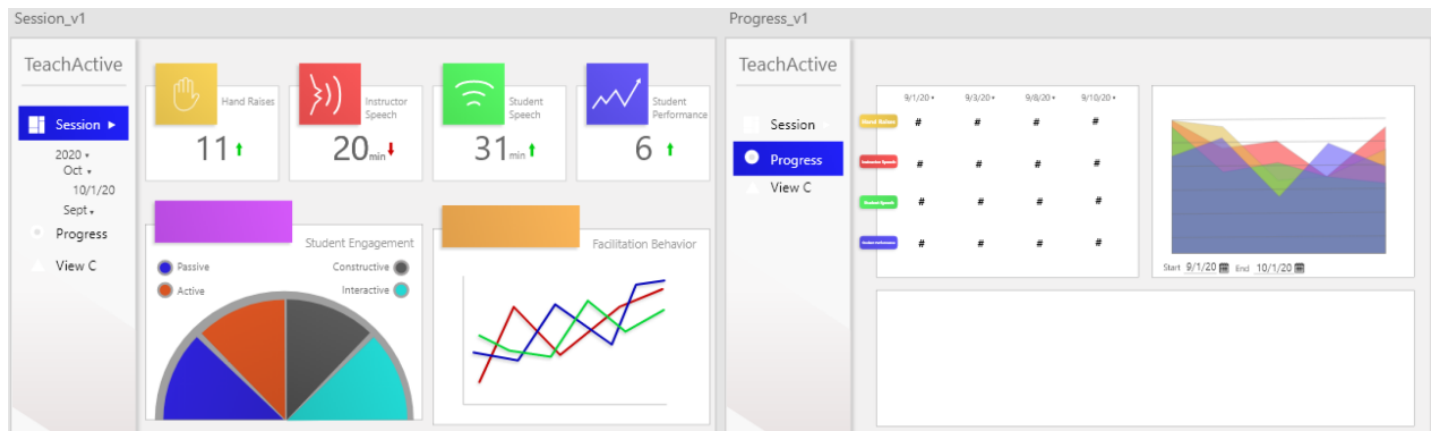

Figure 1: First prototype of TEACHActive Feedback Dashboard. Instructors see two screens: Session (at left) and Progress (at right). In initial user walkthroughs with this mockup, the division of Session vs. Semester Progress information was deemed effective and kept in future revisions. Data visualization for student engagement and facilitation behavior needed revision.

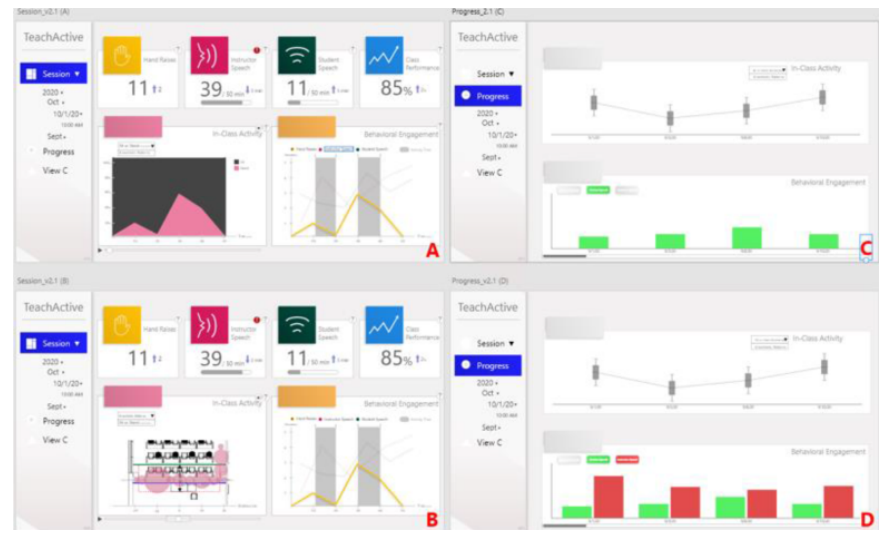

Figure 2: Second prototype of TEACHActive Feedback Dashboard. Data visualizations focused on behavioral engagement were updated and added. Progress section now has comparisons across multiple sessions.

a metric is highlighted with a notification (A). The notification asks them if they are happy with the metric for this session. Selecting Yes to this dismisses the prompt, while selecting No pops up a modal dialog that allows the instructor to set a goal for themselves for their next session. We also added a bar under the metrics that indicates the moments of silence (white) vs speech (colored), and we added a title for each session that instructors can add as recommended during the user walk-throughs. If the instructor navigates to the progress screen they can also see a comparison based Behavioral Engagement component (B). Interacting with the component they are able to select metrics to compare over multiple sessions. Here it can be seen that the instructor speech (red bar) is much higher than the student speech (green bar) on the session recorded on $9 / 1 / 20$ This can be compared to $9 / 3 / 20$ where the instructor spoke less and the students spoke slightly more.

\section{CONCLUSION}

The use of automated systems for classroom observation and feedback is growing, but there is little research on the integration of evidenced-based effective pedagogies with the dashboard design.

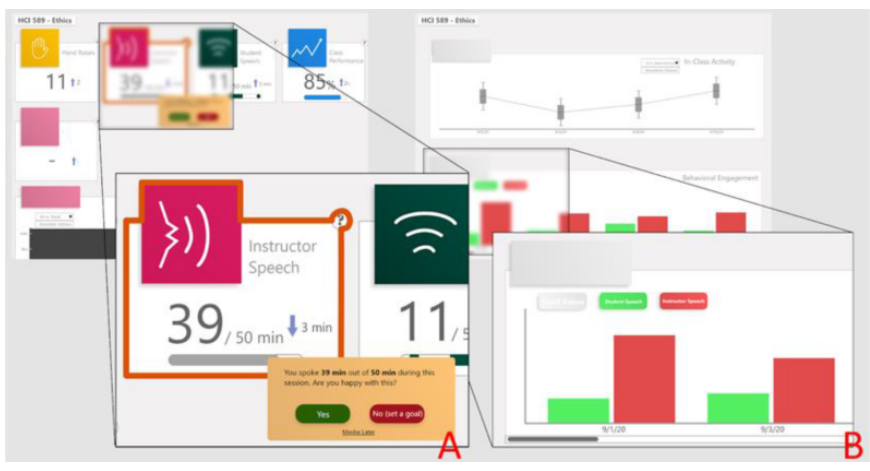

Figure 3: Close-up view of third prototype of TEACHActive Feedback Dashboard, showing new reflection prompts than can appear based on data and a comparison of data from today vs. last session.

With the increasing availability of automated systems in classrooms, it is becoming possible to more accurately document activities, capture data from classrooms, and provide automated feedback to the instructors. TEACHActive offers a novel approach to analyzing automated classroom sensing data and embeds cyber-learning innovation within a theoretically grounded and evidence-based professional development framework. In this paper, we present the first phase of our project: The HCD process of the TEACHActive dashboard designed to support instructors' reflective practice through classroom analytics on active learning strategies employed in engineering classrooms. In the next phase, we will implement the system and the model with cohorts of engineering faculty who will participate in a professional development program on "active learning in engineering classrooms." We will evaluate the longitudinal impact of TEACHActive using surveys, classroom analytics data, faculty reflections, and semi-structured interviews. Transforming raw classroom data into meaningful metrics and then further into practical feedback for instructors will be a valuable contribution to the broader discipline of classroom analytics that can be used by others. 


\section{ACKNOWLEDGMENTS}

This research is supported in part by National Science Foundation under Grant no. 2021118. The opinions, findings, and conclusions or recommendations expressed are those of the author(s) and do not necessarily reflect the views of the National Science Foundation.

\section{REFERENCES}

[1] Karan Ahuja, Dohyun Kim, Franceska Xhakaj, et al. 2019. EduSense: Practical classroom sensing at Scale. Proceedings of the ACM on Interactive, Mobile, Wearable and Ubiquitous Technologies 3, 3: 1-26.

[2] Pengcheng An, Saskia Bakker, Sara Ordanovski, Ruurd Taconis, Chris LE Paffen, and Berry Eggen. 2019. Unobtrusively enhancing reflection-in-action of teachers through spatially distributed ambient information. Proceedings of the $2019 \mathrm{CHI}$ Conference on Human Factors in Computing Systems, 1-14.

[3] John T. Avella, Mansureh Kebritchi, Sandra G. Nunn, and Therese Kanai. 2016 Learning analytics methods, benefits, and challenges in higher education: A systematic literature review. Online Learning 20, 2: 13-29.

[4] Katerina Avramides, Jade Hunter, Martin Oliver, and Rosemary Luckin. 2015 A method for teacher inquiry in cross-curricular projects: Lessons from a case study. British fournal of Educational Technology 46, 2: 249-264.

[5] Robert Bodily, Judy Kay, Vincent Aleven, et al. 2018. Open learner models and learning analytics dashboards: a systematic review. Proceedings of the 8th international conference on learning analytics and knowledge, 41-50.

[6] Robert Bodily and Katrien Verbert. 2017. Review of research on student-facing learning analytics dashboards and educational recommender systems. IEEE Transactions on Learning Technologies 10, 4: 405-418.

[7] I. S. Carvalho and B. Williams. 2009. Facilitating the adoption and dissemination of Active Learning Methodologies in Engineering Education using a Classroom Observation approach. SEFI 37th Annual Conference, 1-4.

[8] Michelene TH Chi and Ruth Wylie. 2014. The ICAP framework: Linking cognitive engagement to active learning outcomes. Educational psychologist 49, 4: 219-243.

[9] Louis Deslauriers, Logan S. McCarty, Kelly Miller, Kristina Callaghan, and Greg Kestin. 2019. Measuring actual learning versus feeling of learning in response to being actively engaged in the classroom. Proceedings of the National Academy of Sciences 116, 39: 19251-19257.

[10] Sidney K. D'Mello, Andrew M. Olney, Nathan Blanchard, et al. 2015. Multimodal capture of teacher-student interactions for automated dialogic analysis in live classrooms. Proceedings of the 2015 ACM on international conference on multimodal interaction, $557-566$

[11] Stephen Few. 2006. Information dashboard design: The effective visual communication of data. O'Reilly Media, Inc.

[12] Scott Freeman, Sarah L. Eddy, Miles McDonough, et al. 2014. Active learning increases student performance in science, engineering, and mathematics. Proceedings of the National Academy of Sciences 111, 23: 8410-8415.

[13] Tracey Garrett. 2008. Student-centered and teacher-centered classroom man agement: A case study of three elementary teachers. The fournal of Classroom Interaction: $34-47$

[14] Dragan Gašević, Shane Dawson, and George Siemens. 2015. Let's not forget: Learning analytics are about learning. TechTrends 59, 1: 64-71.

[15] Dragan Gašević, Shane Dawson, and George Siemens. 2015. Let's not forget: Learning analytics are about learning. TechTrends 59, 1: 64-71.

[16] Graham Gibbs and Martin Coffey. 2004. The impact of training of university teachers on their teaching skills, their approach to teaching and the approach to learning of their students. Active learning in higher education 5, 1: 87-100.
[17] John Hattie and Helen Timperley. 2007. The power of feedback. Review of educational research 77, 1: 81-112.

[18] Charles Henderson, Andrea Beach, and Noah Finkelstein. 2011. Facilitating change in undergraduate STEM instructional practices: An analytic review of the literature. Fournal of research in science teaching 48, 8: 952-984.

[19] Kenneth Holstein, Bruce M. McLaren, and Vincent Aleven. 2018. Informing the design of teacher awareness tools through causal alignment analysis. In International Society of the Learning Sciences, Inc.[ISLS].

[20] Ahmed Kharrufa, Sally Rix, Timur Osadchiy, Anne Preston, and Patrick Olivier. 2017. Group Spinner: recognizing and visualizing learning in the classroom for reflection, communication, and planning. Proceedings of the $2017 \mathrm{CHI}$ Conference on Human Factors in Computing Systems, 5556-5567.

[21] Masaaki Kurosu. 2009. Human centered design. Springer.

[22] Lori Lockyer, Elizabeth Heathcote, and Shane Dawson. 2013. Informing pedagogical action: Aligning learning analytics with learning design. American Behavioral Scientist 57, 10: 1439-1459.

[23] Roberto Martinez-Maldonado, Vanessa Echeverria, Jurgen Schulte, Antonette Shibani, Katerina Mangaroska, and Simon Buckingham Shum. 2020. Moodoo: indoor positioning analytics for characterising classroom teaching. International Conference on Artificial Intelligence in Education, Springer, 360-373.

[24] Amanda Oleson and Matthew T. Hora. 2014. Teaching the way they were taught? Revisiting the sources of teaching knowledge and the role of prior experience in shaping faculty teaching practices. Higher education 68, 1: 29-45.

[25] Rosalind W. Picard. 2011. Measuring affect in the wild. International conference on affective computing and intelligent interaction, Springer, 3-3.

[26] Michael Prince. 2004. Does active learning work? A review of the research. fournal of engineering education 93, 3: 223-231.

[27] Bart Rienties, Quan Nguyen, Wayne Holmes, and Katharine Reedy. 2017. A review of ten years of implementation and research in aligning learning design with learning analytics at the Open University UK. Interaction Design and Architecture (s) 33: 134-154

[28] Kelly A. Rocca. 2010. Student participation in the college classroom: An extended multidisciplinary literature review. Communication education 59, 2: 185-213.

[29] Beat A. Schwendimann, Maria Jesus Rodriguez-Triana, Andrii Vozniuk, et al. 2016. Perceiving learning at a glance: A systematic literature review of learning dashboard research. IEEE Transactions on Learning Technologies 10, 1: 30-41.

[30] Gayane Sedrakyan, Jonna Malmberg, Katrien Verbert, Sanna Järvelä, and Paul A. Kirschner. 2020. Linking learning behavior analytics and learning science concepts: Designing a learning analytics dashboard for feedback to support learning regulation. Computers in Human Behavior 107: 105512.

[31] Gayane Sedrakyan, Erik Mannens, and Katrien Verbert. 2019. Guiding the choice of learning dashboard visualizations: Linking dashboard design and data visualization concepts. Journal of Computer Languages 50: 19-38.

[32] Stylianos Sergis and Demetrios G. Sampson. 2017. Teaching and learning analytics to support teacher inquiry: A systematic literature review. In Learning analytics: Fundaments, applications, and trends. Springer, 25-63.

[33] Katrien Verbert, Sten Govaerts, Erik Duval, et al. 2014. Learning dashboards: an overview and future research opportunities. Personal and Ubiquitous Computing 18, 6: $1499-1514$.

[34] Jackie Walkington, Hans Peter Christensen, and Hanne Kock. 2001. Developing critical reflection as a part of teaching training and teaching practice. European Journal of Engineering Education 26, 4: 343-350.

[35] Alyssa Friend Wise and Yeonji Jung. 2019. Teaching with analytics: Towards a situated model of instructional decision-making. Journal of Learning Analytics 6, 2: 53-69-53-69.

[36] Yesom Yoo, Hyeyun Lee, Il-Hyun Jo, and Yeonjeong Park. 2015. Educational dashboards for smart learning: Review of case studies. In Emerging issues in smart learning. Springer, 145-155. 